\section{AVANCES EN BIOTECNOLOGÍA DE ALIMENTOS}

\author{
Daniel Ramón \\ Biopolis SL \\ daniel.ramon@biopolis.es
}

\section{TRENDS IN FOOD BIOTECHNOLOGY}

Cómo citar este artículo/Citation: Ramón, D. (2014). “Avances en biotecnología de alimentos". Arbor, 190 (768): a151. doi: http://dx.doi.org/10.3989/arbor.2014.768n4005
Copyright: (c) 2014 CSIC. Este es un artículo de acceso abierto distribuido bajo los términos de la licencia Creative Commons Attribution-Non Commercial (by-nc) Spain 3.0.

Recibido: 9 junio 2014. Aceptado: 14 julio 2014.

RESUMEN: Durante miles de años el hombre ha estado usando la genética para lograr la mejora de las materias primas y productos alimenticios terminados. Mediante el uso del cruce sexual y la aparición de mutantes espontáneos se ha generado un gran número de variedades vegetales, razas animales y cepas microbianas. De hecho, la biotecnología de los alimentos es la más antigua de todas las biotecnologías. Recientemente, las técnicas de ADN recombinante se han aplicado en la tecnología de alimentos creando los llamados alimentos modificados genéticamente o alimentos transgénicos. Ejemplos de este tipo de productos son unas patatas transgénicas que funcionan como una vacuna oral contra el cólera, unas levaduras vínicas transgénicas capaces de producir vino con aroma más afrutado o vacas u ovejas que producen leche con altos niveles de proteínas terapéuticas. En cualquier caso, la fecha de partida para el futuro de la biotecnología de los alimentos fue la publicación en 2001 del primer borrador del genoma humano: este descubrimiento abrió la puerta a la búsqueda de genes de nuestro genoma que se activan o desactivan en respuesta a la ingesta de nutrientes específicos. No solo eso, hoy en día también es posible determinar las diferencias genéticas entre individuos que producen diferentes respuestas nutricionales. Además cada día se publican en las bases de datos varios nuevos genomas de animales, plantas o microorganismos que son componentes habituales de nuestra dieta. Algunos casos sobresalientes son los genomas del arroz, la levadura del pan, la bacteria probiótica Bifidobacterium bifidum o patógenos responsables de la intoxicación alimentaria, como Escherichia coli. Estos datos proporcionan información sobre genes clave, con la que es posible diseñar estrategias de mejora por genética clásica o ingeniería clásica, delimitar los mecanismos de defensa para combatir la patogenicidad o definir nuevas funciones fisiológicas. Su aplicación a la alimentación y la nutrición está mucho más próxima de lo que muchos imaginan.

PALABRAS CLAVE: Alimento modificado genéticamente; biotecnología de alimentos; ingeniería genética; nutrigenética; nutrigenómica; riesgo ambiental; seguridad alimentaria.
ABSTRACT: For thousands of years man has been applying genetics to improve both foodstuffs and food products. Using selective breeding and/or spontaneous mutations, a large number of plant varieties, animal breeds and microbial strains have been produced. In fact, food biotechnology is the oldest form of biotechnology. Recently, recombinant DNA techniques have been applied in food technology, creating so-called 'genetically modified foods' (GM foods). Examples include transgenic potatoes able to act as an oral vaccine against cholera, recombinant wine yeasts that produce wine with a fruitier bouquet, and transgenic cows or ewes producing milk with high levels of pharmaceutical proteins. However, the starting date for the future of food biotechnology was the publication in 2001 of the first draft of the human genome. This paved the way for the search for the genes that are activated or deactivated in response to specifics nutrients. It is now also possible to determine the genetic differences underlying individuals' different nutritional responses. Furthermore, every day more genomes of animals, plants or microorganisms that are common components of our diet like rice, bread yeast, the probiotic bacterium Bifidobacterium bifidum or pathogens responsible for food poisoning, like Escherichia coli, are published. This provides information about key genes, making it possible to devise strategies for improvement using classical and genetic engineering techniques, demarcate defence mechanisms to combat pathogenicity, and define new physiological functions. Biotechnology's applications in food and nutrition are more advanced than many people imagine.

KEYWORDS: Genetically modified food; food biotechnology; genetic engineering; nutrigenetics; nutrigenomics; environmental risk assessment; food safety. 


\section{DE LA AGRICULTURA A LA INGENIERÍA GENÉTICA}

Contrariamente a lo que mucha gente piensa, emplear genética en la alimentación y la nutrición no es algo nuevo. Desde hace 12.000 años, en los albores de la agricultura y la ganadería, el hombre ha mejorado las razas de animales de granja y las variedades vegetales comestibles utilizando técnicas genéticas. Comenzó domesticando estos organismos y acabó mejorándolos mediante el empleo de la genética. Para ello se utilizaron varias técnicas. De entre todas ellas las más usadas han sido la hibridación, conocida como cruce sexual, y la aparición de mutantes espontáneos, también llamada variabilidad natural.

En la primera de estas técnicas se cruzan dos organismos parentales portadores cada uno de ellos de una característica agroalimentaria relevante persiguiendo conseguir en el híbrido resultante las características positivas de los dos. Por ejemplo, se puede cruzar una variedad con buenas propiedades organolépticas y que tenga baja productividad con otra con buena productividad en campo pero falta de aroma y sabor. En el híbrido se busca una alta productividad y un buen perfil organoléptico. Dado que cada uno de estos parentales tiene un genoma con varias decenas de miles de genes, lo que ocurre en el nivel molecular en estos cruces es la mezcla al azar de los miles de genes de cada progenitor, de forma que la combinación con los genes adecuados será minoritaria. Pero los mejoradores son capaces de seleccionar los híbridos adecuados entre esa descendencia. Por complicada que parezca esta tecnología ha funcionado magníficamente, de hecho un porcentaje altísimo de variedades vegetales y de razas animales que consumimos en nuestra dieta son productos de procesos de cruce y selección. Así se han conseguido las variedades de trigo con las que se producen las harinas panaderas. Los genomas de estas variedades son un auténtico puzzle de cromosomas que pueden llegar a tener hasta seis pares de cada cromosoma cuando las variedades ancestrales que se cultivaban en el Sudeste Asiático hace 8.000 años tenían dos. Son auténticos paleotransgénicos. Otro ejemplo de mejora por cruce sexual hace referencia a las gallinas ponedoras de huevos. En la década de los cincuenta del siglo pasado las razas más productoras ponían setenta huevos por año. Aplicando técnicas de cruce sexual se han logrado razas que en la actualidad ponen trescientos huevos por año (Hocking, 2010). En realidad, todos los datos aparecidos en los últimos cuatro años sobre secuenciación de genomas indican que un porcentaje mayoritario de las variedades vegetales $y$, en menor medida, razas animales que ingerimos en nuestra dieta son paleotransgénicos que soportan una larga historia de modificaciones genéticas realizadas de forma empírica por el hombre.

Al aplicar la segunda de las técnicas anteriormente mencionadas, la mutación, se seleccionan nuevos individuos mutantes que, también al azar, han modificado o perdido uno o unos pocos de las decenas de miles de genes de su genoma, consiguiendo una nueva combinación mucho más eficaz desde el punto de vista agroalimentario. Un ejemplo claro son las coles. Estos vegetales no existían hace cinco mil años. Son el fruto de una mutación en el genoma de un ancestro evolutivo ya desaparecido sobre un gen que controlaba el desarrollo de las yemas florales. Otras mutaciones en genes que controlaban el desarrollo de las yemas terminales, las yemas laterales o las flores y los tallos explican la aparición de los repollos, las coles de Bruselas o los brécoles, respectivamente. A veces, se ha forzado la aparición de estos mutantes utilizando mutagénesis forzada. Este es el caso de la variedad rosada de pomelo Star Ruby que se obtuvo por irradiación con rayos $\mathrm{X}$ de una variedad previa de pomelo convencional.

Todas las técnicas genéticas mencionadas hasta ahora presentan dos importantes limitaciones: la falta de direccionalidad y la imposibilidad de saltar la barrera de especie. Con respecto a la primera, es imposible conseguir agrupar selectivamente en el descendiente de un cruce los genes deseados de un parental y del otro. De la misma forma, mutar selectivamente un único gen de un genoma es imposible. En cuanto a la barrera de especie, no se puede mutar una zanahoria hasta conseguir una nueva variedad que tenga el contenido en resveratrol de la uva, ni es posible llevar a cabo un cruce sexual entre estos dos vegetales. Hace poco más de treinta años, algunos investigadores norteamericanos trabajando en biología básica descubrieron la forma de hacer moléculas híbridas (o recombinantes) de DNA proveniente de dos organismos distintos. Mediante estas técnicas, denominadas en global ingeniería genética, es posible dirigir la mejora genética al seleccionar el fragmento del genoma que contiene el gen deseado y también saltar la barrera de especie. En esencia consisten en tomar el gen deseado del genoma de un organismo donador e introducirlo en el genoma de un organismo receptor generando un organismo modificado genéticamente (abreviadamente OMG). Por supuesto estas técnicas se pueden utilizar en la agricultura y la alimentación. Cuando se aplican se logran los llamados alimentos o cultivos transgénicos. 
Conviene destacar que hay tres diferencias notables entre las técnicas genéticas convencionales y la ingeniería genética. Con la ingeniería genética se direcciona la modificación genética introducida, se hace de forma más rápida y eficaz y, como anteriormente se mencionó, se puede saltar la barrera de especie. La última de ellas puede afectar a determinados grupos de consumidores, sobre todo si los genes transferidos son de los denominados de reserva ética. Por ejemplo, la expresión de genes provenientes del genoma de un animal en un genoma vegetal o de genes provenientes de genomas de animales que presentan limitaciones de ingesta para alguna religión o grupo étnico (Omobowale, Singer y Daar, 2009).

\section{LOS ALIMENTOS Y CULTIVOS TRANSGÉNICOS}

Es fácil definir qué es un alimento transgénico. Es aquel en cuyo diseño se han utilizado técnicas de ingeniería genética. En la Unión Europea su comercialización está bajo sospecha por cuestiones que tienen más que ver con un debate ideológico que con un debate científico ( $v i d$. infra). En otras partes del planeta su uso aumenta año tras año. De hecho, no ha existido otra nueva tecnología que se haya impuesto a la misma velocidad en la historia de la agroalimentación. Para comprenderlo basta entender el aumento de la superficie mundial con cultivos transgénicos. Siguiendo los datos de la organización International Service for the Acquisition of Agri-biotech Applications (http://www.isaaa.org/), en el año 2013 se cultivaron 175.2 millones de hectáreas de plantas transgénicas en el planeta, lo que supone el $10 \%$ de la superficie sembrada en el planeta. En total 27 países cultivaron transgénicos. Merece la pena destacar que en este año el $90 \%$ de los 18 millones de agricultores que cultivaron transgénicos vivían en países pobres y sembraron más del $50 \%$ de la superficie mundial de transgénicos. En Europa solo ocho países, entre ellos España, cultivaron transgénicos. Desde el año 1996 en que se sembró masivamente el primer cultivo transgénico se ha multiplicado por 94 la superficie cultivada con transgénicos y se han tomado más de 100 millones de decisiones positivas de reutilización de semillas transgénicas. Todos estos datos deberían llamar a la reflexión a aquellos que de forma sistemática se oponen a esta tecnología.

Los primeros alimentos transgénicos que se han comercializado son vegetales transgénicos comestibles que resisten el tratamiento con herbicidas o el ataque de distintas plagas. Se les conoce con el nombre de primera generación de transgénicos y cubren casi la totalidad de los que ahora se comercializan. Han sido los primeros en desarrollarse porque dependen de un único gen y, por lo tanto, su generación es relativamente sencilla y también porque se trata de desarrollos con indudable interés comercial para los agricultores, lo que asegura su venta.

La mayoría de las plantas transgénicas resistentes a herbicidas lo son al glifosato, un compuesto que inhibe la acción de la enzima condensadora de fosfoenolpiruvato, un paso clave en la síntesis de aminoácidos aromáticos. Se han seguido dos estrategias para construir plantas transgénicas resistentes a este herbicida. En la primera se ha aumentado la dosis génica del gen diana desequilibrando la relación cantidad de herbicida/cantidad de dianas. En la segunda se han buscado mutaciones en el gen que codifica la enzima condensadora, de forma que el sitio activo de unión al herbicida ha variado y ya no se produce la inhibición. El empleo de estos cultivos transgénicos va unido a la siembra directa, una práctica agrícola que consiste en espolvorear la semilla sin roturar el campo y tratar inmediatamente con el herbicida (Gianessi, 2005). Usando esta doble tecnología, en Argentina se han alcanzado rendimientos de más de 6 toneladas de haba/Ha con una reducción importante del consumo energético y la erosión, unida a un aumento de la biodiversidad. En la campaña 1994-95, la última sin soja transgénica, los agricultores argentinos gastaban 78 dólares/Ha en herbicidas. Hoy gastan 37 dólares/ Ha y se ha producido una bajada del $90 \%$ global en el consumo de estos plaguicidas. En cuanto a las plantas resistentes a plagas, se han generado variedades comestibles con resistencia a viroides, virus, bacterias, hongos o insectos (Christou, Capell, Kohli, Gatehouse y Gatehouse, 2006). El desarrollo más conocido es la expresión de la proteína insecticida Bt de la bacteria Bacillus thuringiensis en distintas plantas, entre ellas el algodón o el maíz, produciendo resistencia al ataque por este gusano. Se les denomina cultivos Bt y su productividad en campo es superior a la de los cultivos convencionales si hay incidencia de la plaga. Además dan lugar a reducciones drásticas del uso de insecticidas. Como prueba basta recordar que el uso en India del algodón $\mathrm{Bt}$ ha reducido el consumo de insecticidas un 70\% (Quaim, 2010). En la Unión Europea está autorizada la comercialización de soja transgénica resistente al glifosato y del maíz transgénico Bt; ahora bien, ninguno de estos dos cultivos se utiliza directamente en alimentación humana. Se usan como base para la preparación de piensos animales o en la obtención de almidones o jarabes de glucosa de maíz y de lecitinas o fitoesteroles de soja. Estos ingredien- 
tes se utilizan en la formulación de miles de alimentos que deben hacer constar en su etiqueta la procedencia transgénica.

Pero hay más alimentos y cultivos transgénicos. Son la segunda generación de alimentos transgénicos y en ellos la modificación genética introducida afecta a las propiedades físico-químicas, organolépticas o nutricionales. Se han llevado a cabo en vegetales comestibles, en animales de granja y en microorganismos responsables de fermentaciones alimentarias. Por supuesto entrañan mayor complejidad tecnológica pues suelen afectar a varios genes, por eso se han conseguido más tarde. Algunos de ellos están afectados en propiedades físico-químicas como por ejemplo el proceso de podredumbre. En este sentido se han conseguido tomates transgénicos que tienen disminuida la expresión del gen que codifica la enzima poligalacturonasa, consiguiendo una reducción de hasta un $80 \%$ de la actividad y un retraso considerable en la podredumbre del fruto (Sanders y Hiatt, 2005). En ocasiones se han mejorado las propiedades organolépticas. Este es el caso de la construcción de levaduras vínicas transgénicas que tienen mayor aroma afrutado.

Ahora bien, donde más atractivo resultará el empleo de la ingeniería genética será en su uso para paliar los problemas de déficit nutricional presentes en muchos alimentos. Existen ya multitud de alimentos transgénicos mejorados en cuanto a su composición nutricional (Tabla 1). Merece la pena comentar un par de ellos. El primero es el denominado arroz dorado. Se trata de un arroz transgénico en el que se han introducido tres genes que permiten que este cereal contenga $\beta$-caroteno (Ye et al., 2000). Su uso, previsto para el año 2014, permitirá eliminar el problema crónico de avitaminosis en países pobres del Sudeste asiático y Latinoamérica donde la base de la dieta es el arroz. Según datos de OMS, este problema nutricional produce la muerte de dos millones de niños cada año y condena a la ceguera a 250.000 niños en el mismo período de tiempo. El segundo ejemplo es la creación de un tomate transgénico donde se han expresado dos genes de la planta Antirrhimum majus que codifican dos factores transcripcionales (Butelli et al., 2008). El resultado son tomates que acumulan antocianos en concentraciones comparables a las que se encuentran en los arándanos o las moras. Estos tomates tienen una tonalidad púrpura y han sido usados en un análisis preclínico en ratones mutantes Trp53 (-/-) susceptibles en el desarrollo de cáncer, demostrándose que el grupo alimentado con estos tomates transgénicos no desarrollaba tumores mientras que el grupo de ratones mutantes alimentados con tomates convencionales los desarrollaba.

\section{3. ¿CÓMO SE EVALÚAN LOS TRANSGÉNICOS?}

Como anteriormente se indicó, en la Unión Europea hay un debate en torno a la comercialización de los alimentos transgénicos. Se trata de un debate ideológico, excesivamente politizado y carente de datos técnicos. Baste recordar que en la Unión Europea los alimentos obtenidos por técnicas clásicas de biotecnología, incluida la mutación con agentes mutagénicos, no precisan de una evaluación sanitaria. Por el contrario, los alimentos transgénicos la requieren obligatoriamente antes de su comercialización. Para ello se siguen las directrices de FAO y OMS que durante años establecieron sus propios grupos de trabajo sobre la seguridad para el consumidor de los nuevos alimentos transgénicos, concediéndole prioridad a la elaboración de principios científicos para su evaluación (Kuiper, Kleter, Noteborn y Kok, 2001). Estas directrices implican evaluar el contenido nutricional, la posible presencia de alérgenos y el nivel de toxicidad.

En cuanto a la composición nutricional se sigue el criterio de la equivalencia sustancial. Es utilizado por la normativa europea sobre la comercialización de alimentos transgénicos que otorga dicha categoría a aquellos alimentos transgénicos cuya composición nutricional y características organolépticas son iguales a aquel del que proviene, con la única excepción del nuevo carácter introducido por ingeniería genética. Todos los alimentos transgénicos comercializados hasta la fecha cumplen este requisito. Para evaluar la alergenicidad se siguen los criterios de FAO, OMS y el grupo Codex ad hoc Intergovernmental Task Force on Foods Derived from Biotechnology. Esto implica que para cada alimento transgénico se evalúa el análisis de homología y similitud estructural entre la proteína transgénica y alérgenos conocidos y también la posible identificación de epítopos que, por su secuencia en aminoácidos, puedan interaccionar con la inmunoglobulina $\mathrm{E}$, epítopos de células $\mathrm{T}$ o motivos estructurales significativos. También para algunos casos incluye el estudio de la digestibilidad de la proteína transgénica en sistemas simulados de fluidos gástricos e intestinales y estudios de exposición ocupacional. Todos estos trabajos cobran especial relevancia si el organismo donador del gen tiene un pasado de alergenicidad. Finalmente, para llevar a cabo los estudios toxicológicos, si hay equivalencia sustancial se focalizan en la proteína transgénica. Se requiere información sobre su carcinogenicidad, genotoxicidad, 
Tabla 1. Algunos alimentos y cultivos transgénicos mejorados en su composición nutricional desarrollados hasta la fecha

\begin{tabular}{|c|c|}
\hline FENOTIPO MEJORADO POR TRANSGENIA & COMPUESTO DIANA \\
\hline \multirow[t]{7}{*}{ Mejora del contenido en vitaminas } & Aumento del $\beta$-caroteno en arroz o tomate \\
\hline & Aumento del contenido en vitamina A del maíz \\
\hline & Aumento de carotenoides en colza \\
\hline & Aumento de ácido fólico en arroz, lechugas, tomates \\
\hline & Sobreproducción de ácido fólico por bacterias lácticas \\
\hline & Aumento de vitamina $\mathrm{C}$ en lechuga \\
\hline & Aumento de $\alpha$-tocoferol y tocotrienol en maíz \\
\hline \multirow[t]{3}{*}{ Mejora del contenido proteico } & Aumento de lisina en arroz, maíz, patata, remolacha y soja \\
\hline & Aumento de metionina en arroz, girasol y maíz \\
\hline & Aumento global del contenido en aminoácidos en arroz y patata \\
\hline \multirow[t]{3}{*}{ Cambios en la composición de aceites y grasas } & Disminución de ácido linolénico y aumento del ácido oléico en soja \\
\hline & Aumento de ácido esteárico en algodón y colza \\
\hline & Aumento de ácido araquidónico y eicosapentanóico en mostaza \\
\hline Biofortificación de minerales & Aumento de hierro en arroz, guisante y maíz \\
\hline \multirow[t]{5}{*}{ Aumento de flavonoides } & Aumento de genisteína en alfalfa \\
\hline & Aumento de flavonoles en tomate \\
\hline & Aumento de antocianos y flavonoides en arroz \\
\hline & Producción de resveratrol en patatas \\
\hline & Sobreproducción de resveratrol en levaduras vínicas \\
\hline \multirow[t]{4}{*}{ Otros desarrollos de interés nutricional } & Reducción de linamarina en mandioca \\
\hline & Aumento de fructanos en remolacha \\
\hline & Diseño de plantas y microorganismos antialergénicos \\
\hline & Diseño de vacunas orales \\
\hline
\end{tabular}

metabolismo, toxicidad crónica y subcrónica y toxicocinética. Si no hay equivalencia sustancial o existen indicaciones de ocurrencia potencial de efectos no intencionados, se debe estudiar todo el alimento. En estos casos se llevan a cabo estudios de toxicidad de noventa días en roedores con las dosis máximas que no produzcan desequilibrios nutricionales. En todos los alimentos transgénicos comercializados hasta la fecha se han llevado a cabo todos estos controles, concluyéndose que no existe un solo dato científico que indique que dichos alimentos, por el hecho de ser transgénicos, representen un riesgo para la salud del consumidor superior al que implica la ingestión del alimento convencional correspondiente. Esta opinión es defendida por la propia OMS (http://www.who.int/ fsf/GMfood/). Por todo ello podemos concluir que los alimentos transgénicos son los más evaluados en toda la historia de la alimentación y no hay datos científicos que detecten riesgos inaceptables para la salud del consumidor.

En cuanto a la evaluación del impacto ambiental de los cultivos transgénicos las cosas son más complejas, ya que hay una falta de conocimiento y metodologías para analizar riesgos medioambientales, tanto de las plantas transgénicas como de las convencionales (Conner, Glare y Nap, 2003). Aun así, hay que recordar que es preciso evaluar centenares de plantas trans- 
génicas en el invernadero antes de comenzar con algunas de ellas los trabajos de campo. A este proceso se le denomina liberación controlada al ambiente y es obligatorio llevarlo a cabo en distintos ecosistemas y durante diferentes campañas antes de obtener el permiso de comercialización. La experiencia con las mismas demuestra que no hay nuevos riesgos asociados al uso de plantas transgénicas (Jank y Gaugitsch, 2001). Los riesgos son los mismos que con las plantas convencionales, es decir, la posible transferencia de los genes exógenos desde la variedad transgénica a variedades silvestres, el descenso de la biodiversidad en el entorno y, en el caso de las plantas resistentes a plagas, el ataque a organismos distintos del diana. Por ello la cuestión clave es conocer si el empleo de transgénicos acelerará la aparición de estos riesgos. Parece claro que no, siempre que se mantengan y mejoren las normas de evaluación que empleamos actualmente con las plantas transgénicas.

En cuanto a los posibles riesgos y beneficios económicos, la cuestión difiere en función de la parte del planeta donde la planteemos. Por ejemplo, en la República Popular China desde la década de los ochenta existe una apuesta decidida por la transgenia, al extremo de que el Programa Nacional de Biotecnología del gobierno chino ha financiado proyectos sobre más de 130 variedades transgénicas y 100 genes concretos (Huang, Rozelle, Pray y Wang, 2009). Por su parte el gobierno hindú financia 48 proyectos de plantas transgénicas que afectan a 15 cultivos distintos. Se han generado plantas transgénicas de relevancia como variedades de arroz transgénicas resistentes a sequía y salinidad, arroz con provitamina A libre de marcadores de resistencia, patatas y arroz con mayor contenido proteico o patatas transgénicas Bt. Si analizamos Latinoamérica podemos ver que el $98 \%$ de la soja cultivada hoy en Argentina es transgénica. En el primer semestre del 2002, en plena debacle económica por el corralito, el $60 \%$ de los ingresos que entraron en Argentina llegaron por exportación de soja transgénica. Se supone que, de forma directa o indirecta, la soja transgénica da empleo a un millón de argentinos (Burachik, 2010). En Brasil no estaba autorizada la plantación de soja transgénica, pero existía tráfico ilegal de soja transgénica desde agricultores argentinos a brasileños. En su primera campaña electoral el Presidente Lula defendió el rechazo a los transgénicos. Tras llegar al poder comprobó que el $40 \%$ de la soja plantada en Brasil era ilegalmente transgénica, por lo que decidió conceder en el año 2003 una medida precautoria para comercializar de forma transitoria la soja transgénica ilegalmente producida. Desde entonces se aprobó la comercialización de soja transgénica y su producción se ha disparado, de forma que Brasil es el segundo cultivador mundial de transgénicos (Fontes, 2003). En África se han dado casos complicados. Zambia ha rechazado ayuda humanitaria en forma de maíz transgénico aduciendo informes de organizaciones ecologistas sobre el potencial cancerígeno de dicho producto. Estas afirmaciones carecían de datos científicos que las avalaran. Aun así, la apuesta decidida por la transgenia de Sudáfrica y las más recientes de Burkina Faso y Egipto plantean un futuro esperanzador (Paarlberg, 2010). En la Unión Europea la situación es distinta y el avance de los transgénicos es muy lento (Ramón, MacCabe y Gil, 2004).

\section{LA SITUACIÓN DE LA BIOTECNOLOGÍA DE ALIMENTOS EN ESPAÑA}

Los laboratorios públicos españoles ocupan posiciones de privilegio en la investigación en biotecnología de alimentos en la Unión Europea. Hay excelentes grupos de investigación, tanto en el Instituto Nacional de Investigaciones Agrarias y en sus antiguos centros transferidos a las distintas comunidades autónomas, como en el Consejo Superior de Investigaciones Científicas, así como en muchas de las universidades públicas. Es interesante destacar que a partir de estos grupos de investigación han surgido algunas empresas privadas que se dedican con éxito a la biotecnología de alimentos.

En cuanto a temáticas de trabajo, los grupos españoles que están trabajando en biotecnología de alimentos destacan fundamentalmente en las áreas de la biología molecular de plantas y la microbiología industrial, siendo el aporte en biotecnología de animales o producción de aditivos alimentarios mucho menor.

Lo más importante de todo es que estos grupos han desarrollado una dinámica de trabajo y unos contactos internacionales que han permitido generar la mejor generación de jóvenes españoles dedicada a la biotecnología de alimentos. Además han conseguido que algunos de estos laboratorios sean sitio de referencia mundial donde investigadores extranjeros desean acudir a realizar su estancia postdoctoral o a desarrollar su carrera profesional. Desgraciadamente parte de esta situación se está revertiendo, dada la nefasta política de falta de apoyo a la investigación por parte de las autoridades políticas. Es, sin duda, el fruto de la falta de miras y de altura intelectual de unos dirigentes políticos, de un signo y de otro, muy poco capacitados. 


\section{EL FUTURO QUE NOS AGUARDA: EL EMPLEO DE LA GENÓMICA EN LA ALIMENTACIÓN}

En el año 2001, tras un enorme esfuerzo de investigación pública y privada, se hizo pública la secuencia que conforma nuestro genoma. Desde entonces es posible saber qué genes se activan o desactivan en respuesta a la ingesta de un determinado nutriente. A esta disciplina se la denomina nutrigenómica. También es posible determinar las diferencias genéticas entre individuos que dan lugar a diferentes respuestas nutricionales. Es la nutrigenética (Bouchard y Ordovas, 2012). Además, cada día se secuencian nuevos genomas de animales, plantas o microorganismos de relevancia alimentaria, como por ejemplo el arroz, el cacao, la fresa, el lenguado, la levadura panadera o el probiótico Bifidobacterium lactis Bb12. Con ello es posible conocer sus genes clave y definir estrategias de mejora clásica o ingeniería genética.

Hasta ahora la secuenciación de genomas ha sido una técnica costosa en tiempo y dinero, pero en los últimos años se han descubierto nuevas técnicas de secuenciación masiva que permiten acelerar y abaratar los costes de secuenciación. Por ejemplo, recientemente se han llevado a cabo proyectos de secuenciación masiva en voluntarios humanos, determinándose que varios miles de cepas bacterianas distintas pueblan nuestro tracto digestivo y que existen diferencias entre las poblaciones bacterianas de individuos delgados y obesos (Ley, 2010). También se pueden realizar estudios epidemiológicos que permiten definir genes implicados en metabolopatías de interés. Por ejemplo, la enzima metil-tetrahidrofolatoreductasa es crucial para mantener los niveles en sangre de homocisteína. Dichos niveles deben ser adecuados porque si aumentan, el riesgo de padecer una enfermedad cardiovascular es muy elevado. Hay individuos con un genotipo denominado TT que presentan una mutación en dicho gen que da lugar a una enzima poco activa. Los portadores de este genotipo tienen un mayor riesgo de desarrollar enfermedades cardiovasculares. Si por secuenciación se detecta la presencia de esta mutación es posible definir una dieta adecuada que puede ayudar a paliar en parte estos problemas genéticos. En este caso una dieta rica en ácido fólico puede contrarrestar el problema del exceso de homocisteína en sangre; por lo tanto, bastará pautar este tipo de dietas en las personas con dicho genotipo para que su riesgo cardiovascular se normalice (Corella y Ordovas, 2010).

De la misma forma se pueden usar animales transgénicos para estudiar el efecto de ingredientes 0 , incluso, alimentos funcionales. Nuestro equipo de trabajo utiliza el gusano Caenorhabditis elegans para analizar la influencia de determinados ingredientes funcionales en el estrés oxidativo, el envejecimiento, la obesidad, la infección por patógenos intestinales (bacterias y virus) e incluso la enfermedad de Alzheimer. Para ello utilizamos un abordaje multidisciplinar que hace uso de gusanos transgénicos, transcriptómica y metabolómica. De esta forma identificamos sobre qué rutas metabólicas actúan los ingredientes y luego lo confirmamos utilizando mutantes. Siguiendo esta estrategia recientemente hemos demostrado que los polifenoles del cacao actúan sobre una sirtuína que señaliza la insulin-like pathway (Martorell et al., 2011).

Por todo lo expuesto en las páginas anteriores podemos concluir que el futuro de la genética en la alimentación es relevante. Cada día queda más atrás la época en que los tecnólogos de alimentos eran expertos en procesos industriales. Se necesitan nuevos profesionales que entiendan la importancia de la biología celular y molecular y de la genética en la búsqueda de nuevos alimentos con mejores propiedades y también en la comprensión de cómo los alimentos ayudan a mantener nuestra salud. Sin duda también se precisarán nuevos tecnólogos de alimentos con conocimientos en control automático de sistemas o nanotecnologías que aporten mejoras en estas disciplinas científicas. La pregunta clave es: ¿está preparada una comunidad científica tan conservadora como la de los tecnólogos de alimentos y nutricionistas a recibir a estos nuevos profesionales? Confiemos en que así sea. 
Bouchard C. y Ordovas, J. M. (2012). Fundamentals of nutrigenetics and nutrigenomics. Progress in Molecular Biology and Translational Science, 108, pp. 1-15. http://dx.doi.org/10.1016/B978-0-12398397-8.00001-0

Burachik, M. (2010). Experience from use of GMOs in Argentinian agriculture, economy and environment. New Biotechnololy, 27, pp. 588-592. http:// dx.doi.org/10.1016/j.nbt.2010.05.011

Butelli, E., Titta, L., Giorgio, M., Hock, H. P., Matros, A., Peterek, S., Schijlen, E. G. W. H., Hall, R. D., Bovy, A. G., Luo, J. y Martin, C. (2008). Enrichment of tomato fruit with health-promoting anthocyanins by expression of select transcription factors. Nature Biotechnology, 26, pp. 1301-1308. http://dx.doi. org/10.1038/nbt.1506

Christou, P., Capell, T., Kohli, A., Gatehouse, J. A. y Gatehouse, A. M. (2006). Recent developments and future prospects in insect pest control in transgenic crops. Trends Plant Science, 11, pp. 302-308. http://dx.doi.org/10.1016/j. tplants.2006.04.001

Conner, A. J., Glare, T. R. y Nap, J. P. (2003). The release of genetically modified crops into the environment. Part II. Overview of ecological risk assessment. Plant Journal, 33, pp. 1946. http://dx.doi.org/10.1046/j.09607412.2002.001607.x

Corella, M. D. y Ordovas, J. M. (2010). Nutrigenomics in cardiovascular medicine. Circulation: Cardiovascular Genetics, 2, pp. 637-651. http://dx.doi.org/10.1161/ CIRCGENETICS.109.891366
Fontes, E. M. (2003). Legal and regulatory concerns about transgenic plants in Brazil. Journal of Invertebrate Pathology, 83, pp. 100-103. http://dx.doi. org/10.1016/S0022-2011(03)00060-0

Gianessi L. P. (2005). Economic and herbicide use impacts of glyphosateresistant crops. Pest Management Science, 61, pp. 241-245. http://dx.doi. org/10.1002/ps.1013

Hocking, P. M. (2010). Developments in poultry genetic research 1960-2009. British Poultry Science, 51, pp. 44-51. http://dx.doi.org/10.1080/00071668.2 010.507333

Huang, J., Rozelle, S., Pray, C. y Wang, Q. (2009). Plant biotechnology in China. Science, 295, pp. 674-677. http:// dx.doi.org/10.1126/science.1067226

Jank, B. y Gaugitsch, H. (2001). Assessing the environmental impacts of transgenic plants. Trends in Biotechnology, 19, pp. 371-372. http://dx.doi. org/10.1016/S0167-7799(01)01732-2

Kuiper, H. A., Kleter, G. A., Noteborn, H. P. J. M. y Kok, E. J. (2001). Assessment of the food safety issues related to genetically modified foods. Plant Journal, 27, pp. 503528. http://dx.doi.org/10.1046/j.1365313X.2001.01119.x

Ley, R. E. (2010). Obesity and the human microbiome. Current Opinion in Gastroenterology, 26, pp. 5-11. http://dx.doi. org/10.1097/MOG.0b013e328333d751

Martorell, P., Forment, J. V., Llanos, R. de, Montón, F., Llopis, S., González, N., Genovés, S., Cienfuegos, E., Monzó, H. y Ramón, D. (2011). Use of Saccha- romyces cerevisiae and Caenorhabditis elegans as model organisms to study the effect of cocoa polyphenols as an antioxidant food ingredient. Journal of Agricultural and Food Chemistry, 59, pp. 2077-2085. http://dx.doi.org/10.1021/ jf104217g

Omobowale, E., Singer, P. A. y Daar, A. S. (2009). The three main monotheistic religions and GM food technology: an overview of perspectives. BMC International Health Human Rights, 9, pp. 18-25. http:// dx.doi.org/10.1186/1472-698X-9-18

Paarlberg, R. (2010). GMO foods and crops: Africa's choice. Nature Biotechnology, 30, pp. 609-613.

Quaim, M. (2010). Benefits of genetically modified crops for the poor: household income, nutrition, and health. New Biotechnology, 27, pp. 552-557. http:// dx.doi.org/10.1016/j.nbt.2010.07.009

Ramón, D., MacCabe, A. P. y Gil, J. V. (2004). Questions linger over European GM food regulations. Nature Biotechnology, 22, p. 149. http://dx.doi.org/10.1038/ nbt0204-149

Sanders, R. A. y Hiatt, W. (2005). Tomato transgene structure and silencing. $\mathrm{Na}$ ture Biotechnology, 23, pp. 287-289. http://dx.doi.org/10.1038/nbt0305-287b

Ye, X., Al-Babili, S., Klöti, A., Zhang, J., Lucca, P., Beyer, P. y Potrycus, I. (2000). Engineering the provitamin $A$ ( $\beta$-carotene) biosynthetic pathway into (carotenoidfree) rice endosperm. Science, 287, pp. 303-305. http://dx.doi.org/10.1126/ science.287.5451.303 